\title{
The challenges of change: exploring the dynamics of police reform in Scotland.
}

\author{
FYFE, N.R.
}

2019

Copyright (C) 2019 The Author(s). DOI: 10.1177/1461355719889463.

Users who receive access to an article through a repository are reminded that the article is protected by copyright and reuse is restricted to non-commercial and no derivative uses. Users may also download and save a local copy of an article accessed in an institutional repository for the user's personal reference. For permission to reuse an article, please follow our Process for Requesting Permission. 


\title{
The challenges of change: exploring the dynamics of police reform in Scotland
}

\begin{abstract}
Despite a long tradition of pessimism regarding the scope for meaningful change in police practices, the recent structural reforms to police organisations in several European countries suggest that significant change in policing is possible. Drawing on recent research into the establishment and consequences of a national police force in Scotland, this paper uses instrumental, cultural and myth perspectives taken from organisation theory to examine how change happened and with what effects. It highlights how police reform involves a complex interplay between the strategic aims of government, the cultural norms of police organisations, and the importance of alignment with wider views about the nature of the public sector. The paper concludes by identifying a set of wider lessons from the experience of organisational change in policing.
\end{abstract}

\section{Context}

Many commentators on police reform tend to be pessimistic about the scope for delivering meaningful change. Skogan's (2008) seminal piece on 'Why reforms fail', identifies no fewer than 11 reasons for how and why the groups within the police are able to frustrate attempts at innovation and organisational change, ranging from resistance by middle managers and front-line officers to competing demands and expectations (see too Bayley, 2008). Others have echoed this pessimism. For Savage, resistance comes from front-line officers who as 'street-level bureaucrats ... dictate how policies are (or are not) translated into actions at the delivery end of the process (Savage, 2007, p.128), while Sparrow (2016) sees a similar pattern of cultures of resistance operating at a street level. Against this background of a seemingly stubborn continuity in police practices in which any attempts at change are 'doomed to repeat' the mistakes of the past, the recent reforms to the structures of policing in many 
northern and western European countries, suggest a potentially different narrative about the effects of large scale organisational change (Fyfe, Terpstra and Tops, 2013). In Scotland, the empirical focus for this paper, the creation of a national police force in 2013 has not only transformed the structure of policing by ending an over 100 year tradition of local municipal forces but also brought about fundamental changes to the governance and narrative of policing (Fyfe, 2014). In terms of governance the previous arrangements which gave a significant role to local government in financing local policing and appointing local chief officers have been swept away and replaced by a new unelected national body, the Scottish Police Authority (SPA). In terms of narrative, the previous legislative foundation for policing set out in the Police (Scotland) Act 1967 defined the role of policing being 'to guard, patrol and watch so as to prevent the commission of offences and preserve order; and to protect life and property', while Police and Fire Reform (Scotland) Act 2012 articulates a new set of Policing Principles in which the focus is on harm reduction and working in partnership with others to ensure the safety and well-being of communities.

Scotland is not alone in witnessing major structural changes to policing (see Fyfe et al, 2013; Fyfe and Terpstra, 2018) yet assessing what has changed as a result of these reforms is a significant challenge. Reform is a process not an event, involving complex negotiations between a range of stakeholders around the practical implementation of high level strategic visions and objectives. Evaluating the effects of reform in terms of change and continuity becomes complex, not least in terms of finding appropriate timescales for assessing the outcomes of reform. Building on previous work and drawing on the findings from a four year evaluation of police reform in Scotland, the purpose of this article is an attempt to understand both the processes that lead to organisational change and an assessment of the outcomes of reform in terms of its effects and wider implications. At the core of this paper, therefore, is an attempt to answer two questions relating to change in policing: first, the 'how' of police reform in terms of how is change enabled; and second, the 'so what' of police reform in terms of what difference do 
these change make. To help navigate a way through the complexities of police reform, the paper draws on a framework for understanding organisational change in the public sector developed by Christensen, Laegreid, Roness and Rovik (2007). The following section outlines how their organisation theory highlights the importance of instrumental, cultural and myth perspectives for understanding change and then uses this framework to consider how police reform in Scotland happened and what changes to policing it has brought about.

\section{Instrument, culture and myth: perspectives from organisation theory}

Christensen's et al (2007) organisation theory of the public sector provides a way of making sense of how formal constraints and external factors combined with internal traditions and cultures shape processes of reform and organisational change. As these researchers observe, 'Public organisations are woven into complex political and social networks of organised interests, citizens, user groups and clients. They experience competing logics, loyalties and sources of influence that are rooted in their organisations political and administrative leadership, as well as in its culture and external environment' (Christensen, et al, 2007, p.9). Three interrelated elements lie at the core of their analysis:

- The choices and intentions of the political leadership and other actors and the way these are expressed through formal structures;

- The constraints inherent in established traditions and cultures;

- The dominant values and norms in the current environment, which influence the possibilities of what public organisations do.

The first of these requires an instrumentalist lens focused on the rationality of the leaders of organisations in bringing about change and the choices they make as they adjust to new goals, managerial signals and shifting external demands. Typically, this involves a combination of elements of 
a hierarchy-oriented instrumental perspective, where the decisions and choices of leaders are central; and a negotiation-based instrumental perspective which allows for the articulation of different interests and elements of compromise and negotiation. Second, to understand the influence of traditions and cultures on organisational change requires a cultural lens focused on issues of norms, values and identity that shape the operation of organisations. It is this cultural perspective which has tended to dominate much of the policing literature on organisational change to date. Police reforms fail, it is contended, because of various forms of internal resistance from frontline supervisors, rank and file officers and mid-level managers (see Skogan, 2008). A third lens through which to view organisational change is what Christensen et al (2007) term the 'myth' perspective. Here the focus is on the broader institutional environment within which organisations operate where they are confronted with particular norms of how they should be designed and function. Organisations try to incorporate and reflect these norms or myths and seek legitimacy within their institutional environment by aligning themselves with these myths. A particularly potent myth within the public sector in general and policing in particular in recent years has been that of New Public Management with its emphasis on enhanced control through centralization and target driven performance management as ways of improving efficiency and effectiveness.

These instrumental, cultural and myth perspectives provide a helpful framework within which to examine how police reform happened in Scotland and to understand its effects and wider implications. As the analysis which follows reveals, however, the boundaries between instrumental, cultural and myth perspectives are often blurred and the precise meanings of these terms will be shaped by the contexts within which they are deployed. The next section considers the path to establishing a national police force, while the following section assesses the different challenges that change has created. 


\section{Making change happen: the path to a national police force}

In September 2011, the Justice Minister of the Scottish Government announced to the Scottish Parliament that legislation would be introduced to establish a national police force. Not only was this the most radical change to policing in Scotland for over 100 years but also one of the largest public sector reforms in the country for a generation. In this section, the instrumental, cultural and myth perspectives outlined will be deployed to help understand how and why that process of change happened. It is important, however, to situate this reform in a slightly longer time frame. Policing in Scotland, like the rest of the UK, has historically been based around local police forces under the command of individual chief constables and accountable to local politicians. Over time the number of local forces has declined from over 100 in the mid-nineteenth century to just eight on the eve of the 2013 reform. In addition to these structural changes, the balance of power over the operation and administration of the local forces has also shifted. Since the late 1990s, the Scottish Government has gradually acquired powers allowing it to be more interventionist in relation to policing and has established national bodies to take responsibility for areas such as training, drug-related crime and forensic services. Against a background of growing concerns that Scotland's structure of regional policing was no longer fit for purpose in terms of being able to deal with increasingly complex forms of criminality at national and international levels, the Scottish Government also established the Scottish Policing Board in 2009, chaired by the Justice Minister, and with a remit to improve the coordination and collaboration between the regional police forces. Increasing centralism was also evident in the growing influence of the Association of Chief Police Officers in Scotland (ACPOS) in formulating national policing policy in ways which limited the autonomy and independence of local chief constables (Donnelly and Scott, 2005). Despite this momentum towards greater centralisation, however, few would have anticipated that this process would accelerate so quickly such that the structure of regional forces that had existed for over 100 years would be swept away and replaced by a national police force 
in 2013. Drawing on instrumental, cultural and myth perspectives provides a way of making sense of this radical change.

\section{Instrumental perspectives}

By early in 2010 the narrative around policing in Scotland articulated by the Scottish Government was being framed by wider concerns about the funding of public sector services as a result of the financial crisis of 2007-8. Policing, it was argued, needed to explore the options for greater efficiency and effectiveness by reducing the duplication in administrative arrangements inherent in the eight force structure. As a result, the Scottish Government established an expert group, the Sustainable Policing Project, comprising senior civil servants and police officers to explore 3 options for reform: enhanced collaboration between the 8 forces; a regional structure comprising 3 or 4 forces, or a single, national police force. The Sustainable Policing Project reported directly to the Scottish Policing Board chaired by the Justice Minister and, viewed through an instrumentalist lens, this relationship was key to bringing about the legislative and policy changes needed to achieve reform. It involved elements of a hierarchyoriented instrumentalism by allowing the Scottish Government to engineer the vertical coordination of reform through maintaining control of the main decision-making bodies, but also facilitated a negotiation-based instrumentalism by allowing relevant stakeholders, including senior police officers, the police unions and local government, to be brought into the process at an early stage through their membership of the Scottish Policing Board.

\section{Cultural perspectives}


While an instrumental perspective highlights the importance of the structural features of the organisation of the reform process being established in ways which allowed for the political leadership within Scottish Government to achieve their aims, from a cultural perspective there was a need to ensure that consideration of the options for reform was informed by the norms and values of the police service itself in order to establish some legitimacy for change within the profession. In the past, this would have been achieved by dealing directly with ACPOS as the main leadership body of Scottish policing, but ACPOS was split on the issue of reform between those who simply wished to preserve the status quo to those ready to embrace radical change, including the option of a national police service. For Scottish Government this presented a 'window of opportunity' (see Terpstra and Fyfe, 2014; Fyfe and Richardson, 2017), allowing them to bypass ACPOS and deal directly with reform-minded members of the police leadership. As the work of the Sustainable Policing Project progressed, a chief police officer was given the overall responsibility of assessing the different options for reform from a policing perspective and the team of civil servants working on the Sustainable Policing Project were relocated from the Scottish Government offices to the Scottish Police College to work alongside a team of police officers (Fyfe, 2014). Symbolically and substantively this was important in allowing the police to have a strong voice in exploring the options for reform. It suggested a cultural shift in the centre of gravity of the reform process: rather than reform being 'done' to the police by government, reform was now being done 'with' the police. Exemplifying this shift, a large number of additional police officers were drafted into the Sustainable Policing Project team as 'professional experts', focused on how different options for reform would impact on a range of functional areas, from local policing to crime investigation (Fyfe and Scott, 2013).

Myth perspectives 
In order to secure broader political legitimacy for police reform, it was important to the deliberations of the Sustainable Policing Project that their work should be informed by relevant evidence 'of popular recipes of what organizations should look like and how they should function'. (Christensen, et al 2017, p.126). During the planning for police reform, engaging with such 'myths' occurred in three important ways. First, the Sustainable Policing Project commissioned a review of the evidence regarding the impacts and implications of police mergers. The review drew together a wide body of research and 'grey literature' to assess the relationships between police force size, structure and performance, and the identification of the risks and lessons learned from past experiences of organizational change (a version of the report was subsequently published as Mendel, Fyfe and den Heyer, 2017). The review highlighted the increasing influence of New Public Management thinking on police organizations internationally and how this has led to the now widespread belief that more centralized structures provide scope for greater top-down control over performance and opportunities for greater efficiency and effectiveness. As Giocomantonio (2015, p.55) observes, 'the rationalized myth of coordination and integration of resources as a means of cutting spending and increasing value' now has widespread currency within police organizations. The review indicated that the available evidence to support the benefits of New Public Management approaches was not only limited and of variable quality, but that strong arguments could be made for either greater decentralization or increased consolidation depending on whether the overall objectives of reform. The report of the Sustainable Policing Project delivered in March 2011 was unequivocal in its support of a national police force. The report concluded that this option 'provides the greatest opportunity to manage change, drive efficiency and in delivering efficiency when the change is complete', while the current 8 forces model 'represents the opposite' (Scottish Government, 2011a, p.5). 
Having come to this conclusion a second important way in which a 'myth' perspective was introduced into the decision-making around police reform was through the Scottish Government's organisation of an international policing summit ahead of the announcement of decision to go ahead with reform. Representatives of several national police forces across Europe were invited to Edinburgh to speak to an audience of police officers and representatives of police authorities about the benefits of national policing arrangements. This summit therefore served an important symbolic purpose by adding legitimacy to the recommendation of the Sustainable Policing Project and reassuring stakeholders that national police forces can deliver efficient and effective policing. But the summit also provided the opportunity to draw in a third myth perspective by allowing the Scottish Government to not only indicate its desire to distance itself from the approach to police reform in England and Wales (which involved reducing the police budget through cuts in officer numbers, something the Scottish Government resolutely refused to do) but also its capacity for 'state building' through its ambition to establish a new national police institution (Fyfe and Henry, 2012). For the nationalist government in Edinburgh, focused on securing independence for Scotland, changes to policing therefore provided the scope to align police reform with a much broader political agenda. It was shortly after this event, in September 2011, that the Justice Minister of the Scottish Government announced to the Scottish Parliament the intention to introduce legislation to establish a national police force in Scotland.

\section{The challenges of change: evaluating the outcomes of reform}

On the $1^{\text {st }}$ April 2013 the new national force, Police Scotland, became operational. Although the first weeks of this new organisation were relatively uneventful, quite quickly the force became the focus of a fierce media and political debate. The Scottish Government maintained that the new force would strengthen connections between the police and local communities and end the postcode lottery of access to specialist policing resources. Critics, by contrast, maintained that 'a one size fits all approach 
to policing' was emerging with a strong focus on enforcement and a significant local democratic deficit (see Fyfe, 2016; Fyfe, et al, 2018). By the end of its first year of operation these two contrasting narratives had become even more entrenched and policing, to use Loader and Spark's(2011) phrase, was increasingly being carried out in a 'hot climate' of growing politicization and media debate. To be sure, Scottish Government and Police Scotland attempted to frame the achievements of the new national force in the positive terms of a New Public Management discourse of enhanced efficiency, effectiveness and 'benefits realisation'. In their Post-implementation Benefits review, for example, Police Scotland (2014) provided a detailed self-assessment of their perceived progress towards improved ability to deliver local community and policing priorities, improved access to specialist resources, and improved collaborative working with partners. But a rather different narrative continued to be articulated in the media and among politicians opposed to reform which focused on a shifting 'culture of control' (Garland, 2001; Fyfe, 2016). The introduction of a performance management system for policing in Scotland characterized by a strong focus on enforcement-related KPIs (key performance indicators), a significant increase in the number of stop/searches being carried out across the country, and a decision to allow armed officers to be deployed on routine patrol, all fuelled a media and political discourse around what was dubbed the 'Strathclydification of policing'. This phrase reflected the framing of the creation of Police Scotland in terms of a 'takeover' by Strathclyde Police (by far the largest of the legacy forces) rather than a 'merger' of eight forces and the adoption of a policing style and set of priorities that reflected the Strathclyde approach, including the widespread use of stop and search and proactive police interventions, a shift away from community engagement and preventative activities, and a focus on violent crime.

Against this background, the remainder of this section focuses in more detail on evaluating the outcomes of reform. As in the previous section it is structured around notions of instrumental, cultural 
and myth perspectives but re-works these ideas to focus on the findings of an instrumentalist evaluation of police reform; the evidence of cultural conflicts over the style and approach to policing associated with Police Scotland; and, as political and public concerns over the new force increased, the attempt to align a new phase of police reform more closely with prevailing myths about public service delivery in Scotland.

\section{Instrumentalist perspectives}

It was against the background of this increasingly frenzied political and media debate about Police Scotland that the Scottish Government commissioned an independent evaluation of police reform which began in February 2015 and ran for 4 years. The evaluation had been carefully framed by the Government as an assessment of progress towards achieving its political aims of reform, namely reduced duplication of back office services, improved access to national capacity and specialist expertise, and strengthened connections with communities. The evaluation was therefore closely aligned with, and informed by, an instrumentalist perspective in terms of an assessment of whether the objectives of the political leadership had been achieved. Based on interviews with a range of national key informants in Police Scotland, Scottish Government, SPA and other criminal justice agencies as well as series of geographical case studies involving local policing teams, local politicians, community groups and the public, the key findings from the evaluation were published in 5 main reports (SIPR et al, $2016,2017,2018,2019 a$ and $2019 b)$. The overall conclusion of the evaluation was that there was plausible and credible evidence that progress had been made to achieving each of the policy intentions although progress was uneven across the three aims. Most progress had been in relation to establishing more equal access to national capacity and specialist expertise (Fyfe, 2018). Since reform new processes had been put in place to access resources via a national Operational Support Division (which 
includes air support, the marine unit, dogs and horses, and firearms) and a national Specialist Crime Division (SCD). Major Investigation Teams (MITs) based regionally and focused on homicides and other serious crime had also been established. Viewed from the perspective of local policing teams many officers felt they could now draw upon resources and expertise which prior to reform they would have had limited or no access to. This was a view particularly voiced by those working in what were previously the smaller forces who now felt that the visibility and availability of Major Investigation Teams and air support had increased. Local officers also recognised the value of being able to access specialist capability when there were major incidents in ways which allowed local policing capacity to remain focused on delivering a local service. Nevertheless, there remained aspects of the implementation of this aim that left local officers believing their was scope for improvement in accessing specialist expertise. The perception among some local officers was that processes for accessing specialist support were quite bureaucratic, particularly when compared with the more informal system for arranging specialist support that existed prior to reform. Some local officers also expressed concerns about the capacity of some specialist teams including the dog and road policing units and scenes of crime officers to meet all the demands that were placed on them and the competition that now exists between regions for resources.

In relation the aim of reduced duplication, the scale of 'back office' functions had declined as a result of the merger of the eight forces, there had been a reduction in the number of senior police officers and civilian staff at management levels, and there were now fewer but larger control rooms. The impacts of these developments In terms of maintaining service delivery, however, has been more challenging. The processes of reducing duplication in support services had led to reductions in the numbers of civilian staff across Police Scotland with the result that some of the responsibilities, for which civilian staff had previously provided assistance, were now more commonly carried out by police officers, such as dealing with public inquiries at the front desk in police stations, typing up notes, and running checks on 
databases. The restructuring of resources as part of the process of reducing duplication had also impacted on local policing. Since reform, officers spoke of having to cover wider geographical areas than previously, partly as a result of the closures of other local police stations.

It is in relation to the third aim of strengthening connections with local communities that there was the weakest evidence of progress. The evaluation found a perception among a range of local stakeholders that community engagement and locally based joint initiatives were under pressure and the public were increasingly concerned at the challenges they now faced in making contact with the police due to the closure or limited opening times of some police stations. The public perception was that police engagement in these areas had decreased since reform and local officers also voiced concerns about their capacity to maintain community engagement activities. This was seen partly as a product of taking on additional local responsibilities, changing shift patterns and having to work across wider geographical areas since reform, but also reflected a more general perception that at a national level the expectation from chief officers at a national level was for them to be more focused on response and enforcement rather than engagement. For local officers this experience resulted in being less well-known in local communities which reduced the opportunities for gathering local intelligence. These concerns were underlined by local councillors who described police attendance at community council meetings as being less consistent since reform. Local officers also felt that the decision to shut some police stations or limit their opening hours as a way of dealing with budgetary pressures had made it more difficult for the public to contact the local police. The public, councillors, and community organisations were also aware of station closures and changes in the opening hours of the police stations in their local area and had concerns about the signal this sent to the local community about the accessibility of the local police and the ability to report crime and share information. Following the introduction of the single nonemergency number for Scotland, the limited opportunity for direct telephone communication between the public and their local police officers had also led to some officers voicing concerns that the public 
were now less likely to report low level incidents or suspicious behaviour. Consequently, local officers indicated that they were receiving less information from the community about what was happening in their local area and that some types of low level crimes might be going unreported and therefore not reflected in police crime figures. This concern was shared by the public, councillors, council staff and community organisations who mentioned delays in responses to non-emergency calls and not being able to speak to someone locally. This was seen as a particular issue in rural areas where community organisations also expressed concerns that the public were less likely to report crimes and provide intelligence if they could not speak directly to a local officer.

\section{Cultural perspectives}

While an instrumental perspective on the changes achieved in relation to the Scottish Government's aims of reform provides important evidence of some of the early impacts and implications of police reform, it is from a cultural perspective that some of most significant changes become apparent. A focus on the local experience of reform demonstrates quite clearly how the norms of local policing across much of Scotland were fundamentally reconfigured by the reform process. In terms of the style of local policing, concerns rapidly emerged of a shift away from local community engagement and partnership working and towards a more enforcement focused approach (Fyfe, 2016). This shifting 'culture of control' was exemplified in June 2013, a little over two months after Police Scotland established, when there was a series of raids on saunas connected with the sex industry in Edinburgh. Members of the Scottish Parliament, women's groups, and the sauna owners voiced their concern about the raids on businesses which had, before the merger of Scotland's police forces, been tolerated as part of a harm reduction approach of the former local police force in its dealing with the sex trade in the city. According to the Convenor of the Scottish Parliament's Justice Committee, these raids provided 'quite a 
dramatic example of the fears that local policing - which seemed to be succeeding in a different way in a different place-was being overridden by a national attitude that came from the top'. This view was later endorsed by one of Police Scotland's most senior officers who, in a newspaper article under the headline 'Edinburgh sauna raids show police culture clash', observed:

The sauna raids in Edinburgh challenged a way of policing that had existed for a decade or more in terms of style and methods. The new policy pursued by Police Scotland challenged the approach that police had taken there which was about tolerance and harm minimization' (The Scotsman, 2014).

These observations about the way in which local approaches to policing communities were being overridden by new national policies soon started playing into a broader narrative around police reform as critics sought to highlight the emergence of a policing environment characterized by a significant local democratic deficit, a strong focus on enforcement, and the emergence of a 'one size fits all' approach to policing for the whole of Scotland. The introduction of a performance management system characterized by a strong focus on enforcement targets and proactive policing methods exemplified this approach and was most controversially evidenced by the increasing use of the tactic of 'stop and search' across Scotland. In the nine months following the establishment of new force the number of recorded stops increased in more than two thirds of local authority areas across the country, in some places by over 400 percent, leading to heated political debate about the legitimacy of using these powers on such a large scale (see Murray and Harkin, 2016). Responding to these concerns, the new Scottish Police Authority undertook their own scrutiny of the issue. They highlighted the risks of using stop and search on such a large scale, including the potential to cause 'a loss of confidence within the 
community which could undermine the principle of policing by consent and damage the ability of the police to work in partnership with the community to tackle crime' (Scottish Police Authority, 2014: 4).

A further example which exemplified the emphasis being given to a more enforcement orientated apporach to policing concerned the decision that firearms officers were to carry their weapons while on routine patrol rather than these being kept within a locked compartment in a police vehicle until they were needed. This caused particular concern in the northern area of Scotland which has the lowest recorded crime rates in the country and where the decision had been opposed by local councillors, the local MSP and local MP. The local authority took its concerns to the SPA which took the view that this was an operational matter for the chief constable and thus an area in which they could not intervene. This left councilors feeling that they were powerless to influence decisions taken at a national level.

The cumulative effect of these developments was a growing sense that the approach to policing in Scotland was now increasingly out of step with the broader public policy agenda in the country. The focus on enforcement rather than engagement, reaction rather than prevention, and centralized, target-driven decision-making rather than local autonomy and discretion, all indicated that the priorities of policing conflicted with the so-called 'Scottish approach' to public policy advanced by the nationalist government (Cairney et al, 2016). The growing concern of a range of police oversight bodies, including the Scottish Parliament, the Scottish Police Authority and Her Majesty's Inspectorate of Constabulary for Scotland was evident in series of reports that were highly critical of police practice (see SPA, 2014, 2015, 2016; HMICS, 2015). This eventually led to the resignation of the first Chief Constable of Police Scotland and the appointment of a successor determined to re-establish the institutional legitimacy of the police force. 


\section{Myth perspectives}

Soon after the appointment of the second Chief Constable of Police Scotland in 2016, work began with the Scottish Police Authority to develop a new vision for policing that would be more strongly aligned with the discourse around public policy in Scotland. This highlights the importance of a myth perspective for understanding organisational change because this new vision, entitled Policing 2026: $a$ 10 year strategy (Police Scotland and Scottish Police Authority, 2017) quite deliberately aims to resonate with the nationalist Government's agenda for public services in Scotland.

The Policing 2026 strategy is framed in terms of an analysis of why further change is necessary following the police reform, what needs to change and how that change will happen. The strategy focuses on how the demands made on policing are increasingly focused on issues of vulnerability rather than crime, with only $20 \%$ of incidents reported to the police leading to a crime being recorded. This feeds into what needs to change under the new strategy, with priority given to improvements in how the police deal with issues of protection and prevention in relation to vulnerable populations, the need to enhance engagement with local communities, and the increasing use of knowledge to drive innovation. In terms of how this change will happen, the strategy talks of empowering decision-making at a local level within Police Scotland, strengthening partnership working, and investing in new technologies and the development and well-being of the workforce.

The Policing 2026 strategy document illustrates how police reform is very much a continuing process, in which one set of changes soon become entangled in a new set of strategies and priorities which then poses challenges for any assessment of the impacts of reform because these become enmeshed in overlapping phases of organisational change. From a myth perspective, however, the Policing 2026 strategy signals a fundamental shift away from the discourse of New Public Management and an attempt to align Police Scotland more closely with the wider public policy landscape in Scotland with its 
focus on prevention, partnership, and communities. Ever since devolution in Scotland there has been a focus on whether a distinctively 'Scottish approach' to policy and policy making (Cairney et al, 2016) exists. In the early 2000s this was defined in quite vague terms of a more consultative style of policy making than elsewhere in the UK, but was given more definition from 2007 when the Scottish National Party-led government introduced set out a national framework of policy outcomes that would be achieved through greater collaboration at a community level. A landmark report for the Scottish Government from the Commission on the Future Delivery of Public Services (2011) provided more impetus towards a Scottish approach by recommending 'a decisive shift towards prevention', and from 2013 the Scottish Government has emphasised the importance of data and evidence to improve the performance of public service and the need for citizens and communities to have a strong voice in service provision. From a myth perspective, the Policing 2026 strategy therefore heralds not just a new phase of reform but a re-positioning of Police Scotland within the Scottish public policy landscape which aims to help it regain greater political and institutional legitimacy. While too early to assess whether this new strategy has led to a significant shift in policing at street- level, in terms of policy discourse it does represent a major change in the framing of policing in Scotland with a focus on prevention and protection rather than enforcement, and on responsiveness to local needs rather than centralized decision-making.

\section{Concluding comments: the wider lessons of change}

This account of police reform in Scotland has highlighted both the processes and challenges of change associated with large scale structural reforms in contemporary policing. Enabling a process of change requires carefully managing the complex interplay between the intentions of political leaders (captured through an instrumental perspective), ensuring these intentions resonate with the values of police 
organisations (the focus of cultural approaches), and establishing alignment with wider norms about efficiency and effectiveness in public service delivery (the concern of myth perspectives). Combining these three perspectives provides a rich understanding of how change happens in police organisations in particular and the public sector more generally. These three perspectives also provide important insights into the outcomes of change. This paper has shown how reform has realised some of the strategic intentions of political leaders when assessed in narrowly instrumental terms by improving access to specialist resources and reducing levels of duplication. But reform has also encountered major challenges. These are partly cultural, as the different styles and approaches to policing that had existed across Scotland in the past rubbed up against the 'one size fits all' approach of Police Scotland; and partly associated with myths regarding the appropriate functioning of public services as Police Scotland found itself increasingly out of step with wider political norms regarding the priorities of service delivery. Its focus on a heavily centralised, enforcement focused model was at odds with a more partnership and prevention orientated view held by the Scottish Government and has resulted in a new phase of reform centred around the Policing 2026 strategy.

Against this background, what are the wider lessons that can be learned from Scotland's experiences of organisational change in policing? First, there is a need for 'expectations management'. The narrowly instrumental view of police reform often held by political leaders, that assumes it can quickly deliver improvements in efficiency and effectiveness, can be unhelpful and perpetuate the myth that reform is an event rather than a process. While some aspects of reform do happen quickly, such as the appointment of new leadership teams and establishing new structures, more fundamental changes around culture and strategy are often the focus of complex processes of negotiation and implementation and take longer to achieve. Indeed, this is a key finding from the analysis of other recent police reforms in Europe and elsewhere where change has taken longer and been more complex than anticipated at the outset of the reform journey (see Terpstra and Fyfe, 2013; Fyfe and Terpstra, 
2018; Terpstra, Fyfe, and Salet, 2019; SIPR et al, 2019a). This connects to a second wider lesson regarding police reform which is the need to embed a theory of change into the reform process. It is clear from the Scottish experience that the strategic aims of reform were only loosely coupled to an understanding of the causal connections between any pre-conditions required to achieve long-term outcomes. The aim of strengthening connections with communities, for example, was seen simply in terms of 'more effective partnership working' and a 'greater ability to deliver local and community policing priorities' (Police Scotland, 2014) with little analysis of how these conditions would be met. Similarly, creating more equal access to specialist support was linked to the 'improved delivery of specialist resources' with little detailed consideration of how this would be achieved. Without a welldeveloped theory of change, which recognises the influence of instrumental, cultural and myth-based perspectives on achieving intended outcomes, police reforms are doomed to repeat the mistakes of the past in the ways described by Skogan over ten years ago in 'Why reforms fail' (2008). If however, future reform programme focus not only on the need for change but also on how change will happen then it is more likely they will achieve their intended outcomes.

\section{Acknowledgements}

This papers draws on research funded by the Scottish Government on the evaluation of police and fire reform in Scotland and I would like to thank the other members of the research team: Simon Anderson, Nick Bland, Amy Calder, James Mitchell and Susan Reid. I would also like to thank the helpful comments of the anonymous referees. The views expressed in this paper are my own. 


\section{References}

Bayley, D. (2008) Police Reform: Who done it?, Policing and Society, 18(1), 7-17.

Cairney, P, Russell, S, St Denny, E, (2016) The 'Scottish approach' to policy and policymaking: what issues are territorial and what are universal?, Policy \& Politics, 44, 3, 333-50

Christensen, T., Laegreid, P., RonessP.G., and Rovik K.A., (2007) Organization Theory and the Public Sector: Instrument, Culture and Myth. London: Routledge

Donnelly, D. and Scott, K. (2010). 'Governance and accountabilities and Scottish policing', in Donnelly, D. and Scott, k. (eds) Policing Scotland, Cullompton: Willan, pp.175-200.

Fyfe N R (2014) A different and divergent trajectory? Reforming the structure, governance and narrative of policing in Scotland, in Brown, J. (Ed), The Future of Policing. London: Routledge, pp. 493-506.

Fyfe, N.R. (2015) ‘Policing Scotland post-reform: a new politics of policing and a shifting culture of control', in Croall, H., Mooney, G. and Munro, M. (eds) Criminal Justice and Society in Scotland: critical perspectives (London, Routledge). , 167-181

Fyfe, N.R (2018) 'The changing ecology and equity of policing: reconfiguring police organisational boundaries in an era of police reform, in Fyfe., N.,Gundhus, H. and Ronn, K (eds) Moral Issues in Intelligence-Led Policing (Routledge, London), pp 246-61

Fyfe, N. R., Anderson, S., Bland, N., Goulding, A., Mitchell, J., \& Reid, S. (2018). Experiencing Organizational Change During an Era of Reform: Police Scotland, Narratives of Localism, and Perceptions from the 'Frontline'. Policing: A Journal of Policy and Practice. doi:10.1093/police/pay052

Fyfe, N.R. and Henry, A. 'Negotiating divergent tides of police reform in the UK', Journal of Police Studies, 2012/4 No. 25, 171-190.

Fyfe, N. R., \& Scott, K. B. (2013). In search of sustainable policing? Creating a national police force in Scotland. In N. R. Fyfe, J. Terpstra, \& P. Tops (Eds.), Centralizing Forces? Comparative perspectives on 
contemporary police reform in Northern and Western Europe (pp. 119-135). The Hague: Eleven International Publishing

Fyfe, N.R. and Richardson, N. (2017) Police reform, research and the uses of expert knolwedge, European Journal of Policing Studies, 5(3), 147-61.

Fyfe, N.R. and Terpstra, J. (2018) Special Issue on Police Reform: Introduction and Overview. . Policing: A Journal of Policy and Practice. doi:10.1093/police/pay071

Fyfe, N R, Terpstra, J, \& Tops, P. (2013) (Eds.), Centralizing Forces? Comparative perspectives on contemporary police reform in Northern and Western Europe, The Hague: Eleven International Publishing

Garland, D. (2001) The Culture of Control: Crime and Social order in Contemporary Society. Oxford: Oxford University Press.

Giacomantonio C (2015) Policing Integration: The Sociology of Police Coordination Work. Basingstoke: Palgrave Hail Y (2016) Local policing in transition. Examining the impacts and implications of police reform in Scotland. Dundee: University of Dundee (PhD Thesis).

HMICS (2015) Independent Assurance Review Police Scotland - Call Handling Final Report. Edinburgh: HMICS Loader, I. and Sparks, R. (2011) Public Criminology. London: Routledge.

Mendel, J., Fyfe, N., and den Heyer, G. 'Does police force size matter? A review of the evidence regarding restructuring police organisations Police, Practice and Research: an international journal, 18(1) 3-24.

Murray, K. and Harkin, D. (2016) Policing in cool and hot climates: legitimacy, power and the rise and fall of mass top and search in Scotland, British Journal of Criminology, 57(4), 885-905. Accessed via online first: https://doi.org/10.1093/bjc/azw007 
Police Scotland (2014) Post-Implementation Benefits Review. Glasgow: Police Scotland. Police Scotland and Scottish Police Authority. (2017). Policing 2026: Our 10 year strategy for policing in Scotland. http://www.scotland.police.uk/assets/pdf/138327/386688/policing-2026-strategy.pdf

Savage, S. (2007) Police Reform: forces for change, Oxford: Oxford University Press.

The Scotsman (2014) 'Edinburgh sauna raids show police culture clash' 30

Scottish Government (2011a) Sustainable Policing Project Phase Two Report: Options for Reform. Edinburgh: Scottish Government.

Scottish Government, (2011b) Renewing Scotland's Public Services, Edinburgh: Scottish Government Scottish Police Authority (2014) Scrutiny Review - Police Scotland's stop and search policy and practice, Glasgow: Scottish Police Authority.

Scottish Police Authority (2015) Inquiry into the public impact of Police Scotland's Firearms Standing Authority. Glasgow: SPA.

Scottish Police Authority (2016) Review of Governance in Policing, Glasgow: Scottish Police Authority. SIPR, Scotcen and What Works Scotland (2016). Police and Fire Reform Evaluation: Year 1 Summary Report. Edinburgh: Scottish Government.

SIPR, Scotcen and What Works Scotland (2017) Police and Fire Reform Evaluation: Year 2 Summary Report. Edinburgh: Scottish Government.

SIPR, What Works Scotland and Scotcen (2018). Evaluation of Police and Fire Reform: Year 3 Thematic Case Study - Partnership, Innovation and Prevention. Edinburgh: Scottish Government. SIPR, What Works Scotland and Scotcen (2019a). Evaluation of Police and Fire Reform: Year 3 International Perspectives on Police and Fire Reform. Edinburgh: Scottish Government. SIPR, What 
Works Scotland and Scotcen (2019b). Evaluation of Police and Fire Reform: Year 4 - Summary of key findings and learning points from the evaluation. Edinburgh: Scottish Government.

Skogan, W.G. (2008). Why reforms fail. Policing \& Society, 18(1), 23-34.

Sparrow, M. (2016) Handcuffed: what holds policing back and the keys to reform, Washington DC, Brookings institute Press.

Terpstra, J.,and Fyfe, N. R. (2013). Introduction: A 'transformative moment in policing'. In N. R. Fyfe, J. Terpstra, and P. Tops (Eds.), Centralizing Forces? Comparative perspectives on contemporary police reform in Northern and Western Europe (pp. 1-22). The Hague: Eleven International Publishing. Terpstra J and Fyfe NR (2014) Policy processes and police reform: Examining similarities and differences between Scotland and the Netherlands. International journal of law, crime and justice 42(4): 366-383. Terpstra J and Fyfe NR (2015) Mind the implementation gap? Police reform and local policing in the Netherlands and Scotland. Criminology \& Criminal Justice 15(5): 527-544.

Terpstra, J., Fyfe, N.R. and Salet, R. (2019) The Abstract Police: a conceptual exploration of unintended change of police organisations, The Police Journal: Theory, practice and Principle, 